\title{
Using Social Networking Sites as Medium of Instruction at Tertiary Education During Covid-19 Situation in Bangladesh
}

\author{
Md. Fajlay Rabbi ${ }^{1,}$ Marzia Khatan Smita ${ }^{2}$, Shoeab Mohammad $^{3}$
}

\begin{tabular}{l} 
AR T ICLE INF O \\
\hline Article History: \\
Received 01.03.2020 \\
Received in revised form \\
22.06 .2020 \\
Accepted \\
Available online \\
01.07 .2020
\end{tabular}

\begin{abstract}
The objective of the study was to investigate the use of social networking sites as medium of instruction at tertiary level during COVID-19 in Bangladesh. All the participants were from various public universities in Bangladesh. Data was collected from both faculty members and students Major findings of the study reveal that (1) Most of the people use Facebook for social networking in Bangladesh; (2) Most of the students and teachers use cellular data for social networking; (3) Most of the faculty members think social networking site is a very easy medium to communicate with students; (4) Anywhere, anytime teaching-learning can be possible with the help of social networking; (5) Most of the respondents think that the students of rural areas in Bangladesh had fewer access in social networking sites due to lack of network support and technology. Ultimately, social networking site can be a very useful tool for teaching-learning in emergency situations where face to face teaching-learning is not possible.
\end{abstract}

C IJERE. All rights reserved

Keywords:

Social networking sites (SNSs), Facebook, COVID-19, teaching-learning in emergencies, Tertiary level.

\section{INTRODUCTION}

The use of information communication technology (ICT) has been recently used a lot in education throughout the world. A variety of software for computers which contributes to education has been developed in this recent year and a number of 1 teachers try to adopt it into their classrooms in order to provide effective teaching and learning opportunities. The progress in technology has led to an integrated society, defying geographical, ethnical, racial and gender boundaries. With the evolution that is taking place, the learning process can definitely make use of the enormous capacity that SNSs offer (ASTD, 2012). Adopting a more social approach to learning is not a new phenomenon, while the aspect of using SNSs singularly does not make the learning process "social". It is also important to note that a social learning process and social media is not the same thing. Additionally, it is a fact that social learning has no association with social media during the inception (McGreal and Elliott, 2004). The definition of social learning is learning from and with others in the context of one's workplace, culture and world. However, mostly it is unintentional and unconscious and working together to solve a problem does not establish a theory for social context. It is just a straightforward collaboration in a workplace. However, on a large scale, social media will be the tools that will enable social learning to take place. Therefore, it is vital that a process to designed for social learning through the social media. To implement such a process; it would be necessary to include collaborative activities offered by social media. But also, a shift is required in the method of instruction is perceived to specifically provide in the form of discrete courses and modules (ASTD, 2012). It is essential to identify the goals of instruction to avoid loss of focus on the objectives, which occurs due to the enthusiasm of using new products and tools.

At present it is known that, Social Networking Sites been attributed most within social software (Selwyn, 2009). The most popular definition for Social Networking Site was given by Boyd and Ellison (2008), who define it as "web-based services that allow individuals to:

- Construct a public or semi-public profile within a bounded system

- Articulate a list of other users with whom they share a connection

- View and traverse their list of connections and those made by others within the system (p.211)

Facebook is a type of Social Networking Site that can be considered a widely famous website for online social networking among students in universities (Kabilan et al., 2010). Facebook and other SNSs are useful and if it should be used as an educational tool for students. Selwyn (2009) suggested that some educators appreciate the ability of Social Networking Sites to re-engage students with their studies. There are also

1.Md. Fajlay Rabbi, Lecturer, Institute of Education and Research, Khulna University, Khulna, Bangladesh, ranjanrabbi@ku.ac.bd , https://orcid.org/0000-0002-3085-7537

2.Marzia Khatan Smita, Lecturer, Institute of Education and Research, University of Chittagong, Chittagong, Bangladesh, mk.marzia@gmail.com, https://orcid.org/0000-0002-0553-3581

3.Shoeab Mohammad, Post-graduate student, Torrens University, Australia, shoeab.mohammad@otorrens.edu.au, https://orcid.org/0000-0001-7688-5691 
opposite reaction of the applications may prevent or disrupt students from engaging in the traditional method of receiving education. On the other hand, some educators considered SNSs as a smart education system in the classroom, while others believe it to be an invasion towards students' privacy (Mendez

et al., 2009). Hosny and Fatima (2012) suggests that SNSs are popular among youths that drive the educators to apply it for enhanced learning. Some of the benefits of using SNSs as learning tool for students are to support collaboration and communication between students, enhance learning, increase students' motivation and provide psychosocial benefits. Social Networking Sites also introduce several problemsoveruse, privacy issues and the lack of protection for intellectual property. In this study, a complete review will be provided to discuss both the benefits of using Social Networking Site as a learning tool for students and as well as discussing the associated problems of using the Social Networking Sites during COVID-19 situation in Bangladesh.

\section{Situation of the Problem}

Coronavirus disease (COVID-19) is an infectious disease caused by a newly discovered coronavirus. Most people infected with the COVID-19 virus will experience mild to moderate respiratory illness and recover without requiring special treatment. Older people, and those with underlying medical problems like cardiovascular disease, diabetes, chronic respiratory disease, and cancer are more likely to develop serious illness. The best way to prevent and slow down transmission is be well informed about the COVID-19 virus, the disease it causes and how it spreads. Protect yourself and others from infection by washing your hands or using an alcohol-based rub frequently and not touching your face. The COVID-19 virus spreads primarily through droplets of saliva or discharge from the nose when an infected person coughs or sneezes, so it's important that you also practice respiratory etiquette (for example, by coughing into a flexed elbow). At this time, there are no specific vaccines or treatments for COVID-19. However, there are many ongoing clinical trials evaluating potential treatments. (WHO,2020)

\section{Aim of the Study}

The aim of the study is to investigate the use of an easy medium such as; social networking sites for teaching-learning process for the tertiary level students during this emergency COVID-19 situations in Bangladesh. Bangladesh went to shut down educational institutions to prevent the pandemic COVID-19 outbreak since March 2020, it might continue until corona situations improved, but day by day Bangladesh is becoming the hotspot in Asia region. So, face to face teaching-learning won't be possible in Bangladesh for longer period of time. To reduce the loss of the tertiary level students, Government suggested to use Zoom software for the continuation of teaching-learning. But due to lack of cellular networks all over the Bangladesh, most of the public university students were unbale to use zoom. But rather they can access social networking site though having poor network at their home.

\section{Methodology}

A social network involves a set of actors and the relations that connect them. This study wanted to explore the educational adaptation of Bangladeshi tertiary level students especially public university students, in particular, during this COVID-19 emergency how this is related to the use of Social Networking Sites. As for SNSs, a fastest-growing and most popular technology with young people is their opportunity to be adopted to accelerate the education adjustment for teachers and students.

- Research Question 1: What kinds of difficulties do Bangladeshi tertiary level students encounter during COVID-19 situations in teaching-learning?

- Research Question 2: How social networking sites are helping the students in teaching-learning during COVID-19

\section{Tool}

Questionnaire and interviews are the main data collection instruments. We examined educational adaptation in tertiary level students and teachers in Bangladesh during COVID-19 students by asking them questions and from the students provided questionnaire regarding their experiences in adjusting and adapting to the study during this COVID-19 life in Bangladesh. It is expected that the mode of research, relying on interaction within a group through debates and arguments, will generate new ideas and data across a range of experiences and opinions. The study examined the adjustment issues by drawing on the participants' 
narrative of their perceptions of the educational adaptation. The interview questions addressed their learning experience, academic difficulties, and use of Social Networking Sites, as follows: what challenges do you face in the new educational environment; do you enjoy or satisfy with your life in COVID-19 situation staying at home; how do you expand your support networks on campus and outside; how often do you use Social Networking Sites; how do you interact with home and local friends online and offline; do you feel Social Networking Sites can help you transmit in your learning experience? Do you think Social networking sites are better than zoom?

\section{Participants}

Participants were 25 Bangladeshi public university students, age between 17-25 from divisional public universities in Bangladesh, both male \& female and 25 public university teachers between age 26-50, both male and female from divisional public universities; participants were collected purposively.

\section{Data Analysis}

This section will report the finding from the questionnaire-

Most of the participants have used more than one kind of Social Networking Sites and most of them reported having educational adaptation difficulties. Students have particularly intense

emotional experiences at the start of COVID-19 when they would be attempting to adapt to the unfamiliar academic situation. Students' support networks play a crucial role to provide

mutual assistance from tertiary level students. Thus, these would alleviate adjustment problems in the early stage: One of the respondents responds like-

"I have a hard time staying at home for a long time during COVID-in Bangladesh, it's nice to use Facebook as a medium of instruction in this pandemic situation. As cellular data is expensive here in Bangladesh and at home, I don't get $4 G$ network support, so Facebook is useful for teaching-learning here

As these tertiary level students adjust in new situation staying at home in Bangladesh, all may be confronted with the following similar challenges and problems, such as, boredom, academic demands, lack of study skills, session jams, mental unwellness. They usually have to reestablish their social networks so as to obtain useful suggestions.

\section{Sharing learning materials with ease during emergency:}

Using FB was a good experience and they will continue to use it after the class to stay in touch with their classmates. In this COVID-19 situation Facebook is a very convenient source to be connected staying at home. If the instructor continues teaching-learning with Facebook with low network signals, students can also be connected and gain learning outcomes staying at home easily and get learning materials from the instructor very easily. It was enjoyable and their first time using a social networking site in the context of learning. It is enjoyable to share documents, videos and slides. 
Table 1: Facebook activities of students' during COVID-19 situations

\begin{tabular}{cc}
\hline Check announcements from the teacher & 10 \\
Comment on classmates' posts & 10 \\
Submit assignments or tasks & 20 \\
Reply to teacher or classmates' & 4 \\
comments & 16 \\
Share some links, photos, or posts & 10 \\
Chat with teacher & 100 \\
Start a discussion & 20 \\
\hline COVID awareness sharing & 10 \\
\hline
\end{tabular}

\section{Collaboration among students during pandemic emergency:}

Social Networking Sites can directly contribute to collaboration and communication. Facebook is famous SNS, which encourage collaboration and foster the creativity of energy to produce shared knowledge that benefits every student (Matthew et al., 2012). Henderson et al. (2010) stated that SNSs are increasingly accepted by educators due to its ability of offering strong communication and collaboration areas for the activities in classes. One of the important features in Facebook is the virtual wall that allows users to easily share ideas and knowledge. Hence, collaborative learning environment can be established that benefits the user and as well as other students who have access to the posts. SNSs promote solid relationship among students via active communications, which highly unlikely would occur during offline mode (Sturgeon and Walker, 2009).

\section{Learning enhancement during emergency:}

Active usage of SNSs will evolve into a learning tool for students that may speed up the learning cycle. Matthew et al. (2012) conducted a study where the in-class learning tool was SNSs and the purpose of the study was to discover the reaction towards learning via SNSs. The direct response from the students that were involved is that despite some technology hurdles, online classes lead to deeper understanding of the materials. Additionally. Wang (2012) reported that Facebook usage in education introduces comprehensive learning that benefits both the students and teachers. It was also found that students are more serious toward online materials as opposed to conventional materials. Facebook used for student's learning provides a personalized experience, however students expect the websites to be more dynamic (Griffith and Liyanage, 2008). This method of teaching-learning enhances students' motivation by encouraging them to focus on the finer details of the task and ultimately improve the quality of their work. The motivation of students in sharing their learning materials proportionally increase the personalization and gratification of the SNS experience (Mazer et al., 2007; Hoffman, 2009). For smooth learning, students' interaction with their teachers and peers are important, where the usage of SNS, namely Facebook provide an excellent virtual space for increased interaction (Wang, 2012).

Students life skills improvement like being social during emergency:

Some psychological benefits also found for the students who use SNSs as a learning tool. Tynes (2007) and Griffith and Liyanage (2008), the two psychological benefits are facilitation of identity exploration and improvement in social cognitive skills. According to Ellison et al. (2007), Facebook utilization as students' 
learning tool leads to psychological well-being psychological and provide benefits for students with low selfesteem and low levels of self-satisfaction. The SNSs are also beneficial in building healthy relationships between students and teachers, which is necessary in any learning environment. According to Sturgeon and Walker (2009), the connectivity between students and teachers through Facebook leads to better communication, resulting in increased engagement between them and better learning environment.

Facebook helps the students to get to know their teachers on a personal level outside of the classroom. Hewitt and Forte (2006) and Mendez et al. (2009) stated that students' perceptions toward teachers improved due to the active interaction in Facebook. In distance learning, SNSs became a popular medium for attaining higher education. As a result of the advancement in communication technology, students can learn without actually attending tutorials or lectures in universities and colleges. Using SNS for students' learning enhances mutual support through the process of learning, while the learner also able to control his own schedule (Minocha, 2009a).

\section{Disadvantages of SNSs for academic purposes:}

Despite the many advantages using SNS as a learning medium for students, naturally there are always drawbacks in a method. Firstly, the major problem is the abuse of SNSs, where it will be used for social reasons rather than educational ones by students. According to the study conducted by Grosseck et al. (2011), majority of students spend long hours in SNSs, Facebook in particular, for social reasons, namely contacting friends and families and sharing photos and videos. However, very little time is spent for learning and academic purposes within SNSs. Junco (2011) conducted a study to investigate the relationship between their uses of Facebook, the time spent preparing for classes and the GPA's earned. For many students, the time spent maintaining SNSs (updating statuses, chatting, etc.) is enormous and it often detracts from the amount of time they have to devote to school work.

One of the examples is, the first thing many students do after arriving home is possibly logging into their favorite sites. The time spent in socializing via SNSs may lead to neglecting their homework, ultimately resulting in poor performance (Mislove et al., 2007). The second concern would be the threat towards students' privacy by using SNSs as a learning tool. According to Griffith and Liyanage (2008), trust, safety and privacy are the major issues related to the usage of SNSs for students' learning and teaching.

The level of online participation among students and their teachers through Facebook also can cause a potential misunderstanding. Many SNSs do not control over information posting on other user's "wall" or on public discussion boards. Anonymous posters can disturb the learning process by posting defamatory messages or discrediting information about educators or students. As a result, such actions can deteriorate the mutual trust between students and their teachers. On the other hand, owing to the online nature of communications in SNSs, teachers and educators may experience difficulty in maintaining their credibility and authority. As a solution, teachers must impose certain limitation and closely monitor students during the utilization of SNSs. This prevents the relationship from becoming too informal (Mazer et al., 2007; Griffith and Liyanage, 2008). The negative impact of SNSs may impact youths at personal level as well, where the increased use of SNSs may lead to various psychological and social problems. Some studies have suggested that the heavy usage of SNSs may result in personality changes and mental disorders, namely attention deficient hyperactivity disorders, difficulties with face-to-face communication and inflated egos. Furthermore, since youths spend enormous amount of time with online activities, conventional forms of communication and socializing significantly decrease, resulting in increased physical isolation. Hence, there are researchers suggesting that SNSs are actually not suitable as a learning tool. However, the fact of SNSs contributing to learning environment cannot be argued, but the potential negative impact could be disastrous. As mentioned earlier, teachers will begin to teach online and without the conventional face-toface interaction, there will be problems in identifying students with special needs. Ultimately, in the long run, SNSs in the classroom could threaten the relationships between teachers and students (Mislove et al., 2007).

\section{Conclusion and Implications}

Based on the interview, the study investigates the relationship between the use of Social Networking Sites and tertiary level students' educational adaptation during COVID-19 pandemic situations. This study demonstrated that Social Networking Sites can lead to building social networks of tertiary level students to 
support their learning during emergencies. Results of this small-scale interview in one location indicated students differ somewhat in their current uses of SNSs. Facebook, as the most popular used in Bangladesh, is perceived as the first choice for tertiary level students to build social networks and awareness. Several significant findings help to better understand these differences. We can imply that Social Networking Sites may become yet the technology that had great potential for improving the higher education experience.

Findings from this study are potentially useful for education administrators and preparing students for studying in emergency situations like COVID-19. It is important for education administrators in universities to realize that they should make an effort to provide more chances for students' providing various opportunities. Thus, this study should be useful to university administrations and education policy makers when considering tertiary level students adapting to emergency situation's teaching-learning.

This study has discussed the multiple benefits and problems associated with the usage of SNSs as learning tool for students. The benefits are potential to establish a collaborative environment, enhancing learning environment and peer engagements and improving every aspect of the social life of a student during COVID-19. Majority of the research works that cover SNSs

supports the above segments, which reveals the advantages of using SNSs effectively in aiding students toward an improved learning approach. However, with any approach, there will be disadvantages and this study had revealed the disadvantages thoroughly. Several solutions had been proposed, namely introducing a method of instruction in the form of discrete courses and modules, setting specific goals and objectives for effective adoption of SNSs as a learning

tool, appointing a trainer to control SNS learning platform with complete authority and finally selecting the appropriate applications within the SNSs for effective teaching-learning process.

\section{Limitation and Future Work}

There are several limitations of this study. First, as a qualitative study, the sample size was small which limited the statistical power to generalize. Secondly, it is also quite possible exist positive bias that the respondents in favor of positive attitude of Social Networking Sites experiences would like to evolve individual interactions online. Future work in this area should seek to include larger numbers of participants to avoid the potential bias in the results.

\section{Discussion}

The implementation of SNSs as an education tool would be significantly challenging. The stakeholders, namely university administrators, lecturers, students, technical support and solution providers, should introduce solutions to address all the barriers meticulously for a successful implementation of SNSs as an education tool.

Surfing Facebook is absolutely not a goal. In the perspective of a learning tool, goals should be exploring, listening, sharing, reflecting and interacting with the tutor, getting new methods for extending classroom discussions and carrying out summative or conductive assessment activities. These are the goals that will determine the suitable kind of SNSs to be used as learning tool during emergency period. In order to avoid any misuse of the SNS, it is important that learners are made aware regarding the purpose of SNSs intended to be used and how those tools should be used. During the utilization of SNSs as a learning tool, a trainer should be appointed as the central controller of the interaction platform. Having a leader in place, learners' participations will be more effective due to the sense of ownership among students. In a strategic approach, this trainer would assign to learners on the kind of updates that are allowed, which directly contributes toward the establishment of goals set for social media as a leaning tool (Australian Flexible Learning Framework, 2013). In other word, the SNS platform will be class, the learners are the students

and the trainer will be the teacher, however in a more technological approach. The conventional SNSs always have many types of tools, it is very useful to select the tools that will be required to address the set of goals in the long run. Finally, to achieve the overall success while carrying out all the solutions, it is vital to consider the actual reason for using SNSs as learning tool in the first place (Mazer et al., 2007). Approaching SNS in this method will ensure that the disadvantages of SNSs on the learning process are curbed and the affordances carefully optimized. 


\section{REFERENCES}

Alshammari, Sultan, Bilal, A., Mohamad \& Rosli, M.S., (2015). The effectiveness of using social network sites as learning tool for students. Research Journal of Applied Sciences, Engineering and Technology, 11, 1220-1226. 10.19026/rjaset.11.2228.

Boon, S., \& Sinclair, C., (2009). A world I don't inhabit: Disquiet and identity in second life and facebook. Educ. Media Int., 46(2): 99-110.

Boyd, D. M., \& Ellison, N.B., (2007). Social network sites: definition, history, and scholarship. Journal of Computer-Mediated Communication, 13(1), 210-230.

Boyd, D.M. \& Ellison, N.B., (2008). Social network sites: Definition, history and scholarship. J.Comput-Mediat. Comm., 13,210-230.

COVID-19 disease retrieved from https://www.who.int/health-topics/coronavirus\#tab=tab_1

Ellison, N.B., Stienfield, C., \& Lampe, C., (2007). The benefits of Facebook "friends:" Social capital and college students' use of online social network sites. J. Comput-Mediat. Comm., 12, 1143-1168.

Griffith, S. \& Liyange,L., (2008). An introduction to the potential of social networking sites in education. Proceeding of the Emerging Technologies Conference, pp: 76-81.

Grosseck,G., Bran, R., \& Tiru,L. (2011). Dear teacher, what should I write on my wall? A case study on academic uses of Facebook. Proc. Soc. Behav. Sci., 15, 1425-1430.

Huijser, H., (2008). Exploring the educational potential of social networking sites: the fine line between exploiting opportunities and unwelcome imposition. Studies in Learning Evaluation Innovation and Development, 5(3),45-54.

Magro, M.J., Ryan, S. D., Sharp, J.H., \& Ryan, K. A., (2009). Using social networking for educational and cultural adaptation: an exploratory study, in Proceedings of the 15th Americas Conference on Information Systems, p. 528, San Francisco, Calif, USA

Okumura, S., (2016). The use of an educational social networking site for English language learning beyond the classroom in a Japanese university setting. Research Bulletin of Education, Vol.11, 2016 